\title{
Essai sur la Vie sans Cesse
}

\author{
Rick Malsick
}

Je n'ai pas d'âme

Jadis $j$ 'en avais une

Plus jamais

Je n'en aurai jamais une autre

Tout ce que j'ai

C'est une boîte

Faite en ébène

Qui reste dans mon coeur

Et dans cette boîte

Il reste des secrets, des souvenirs

Et une seule

Emotion

- Est-ce que cette boîte sera jamais ouverte?

- Non monsieur.

Jamais

La boîte ne sera jamais ouverte

Et je ne peux plus le faire

I1 est trop tard

$J$ 'ai froid

Et je veux voir ma mère 